\title{
Molecular mechanism of azoles resistant Candida albicans in a patient with chronic mucocutaneous candidiasis
}

\author{
Ming-rui Zhang ${ }^{1}$, Fei Zhao², Shuang Wang ${ }^{1}$, Sha Lv', Yan Mou', Chun-li Yao ${ }^{1}$, Ying Zhou ${ }^{1}$ and Fu-qiu Li
}

\begin{abstract}
Background: More and more azole-resistant strains emerged through the development of acquired resistance and an epidemiological shift towards inherently less susceptible species. The mechanisms of azoles resistance of Candida albicans is very complicated. In this study, we aim to investigate the mechanism of azole-resistant $C$. albicans isolated from the oral cavity of a patient with chronic mucocutaneous candidiasis (CMC).

Case presentation: CMC diagnosis was given based on clinical manifestations, laboratory test findings and gene sequencing technique. Minimum inhibitory concentration (MIC) of the fungal isolate, obtained from oral cavity termed as CA-R, was obtained by in vitro anti-fungal drugs susceptibility test. To further investigate the resistant mechanisms, we verified the mutations of drug target genes (i.e. ERG11 and ERG3) by Sanger sequencing, and verified the over-expression of ERG11 and drug efflux genes (i.e. CDR1 and CDR2) by RT-PCR. A heterozygous mutation of c.1162A > G resulting in p.K388E was detected in STAT1 of the patient. The expression of CDR1 and CDR2 in CA-R was 4.28-fold and 5.25-fold higher than that of type strain SC5314, respectively.
\end{abstract}

Conclusions: Up-regulation of CDR1 and CDR2 was mainly responsible for the resistance of CA-R. For CMC or other immunodeficiency patients, drug resistance monitoring is necessary.

Keywords: Chronic mucocutaneous candidiasis, STAT1, Candida albicans, Azoles resistance, Over-expression, Drug efflux

\section{Background}

Chronic mucocutaneous candidiasis (CMC) is a heterogeneous disease in children featured by persistent and recurrent infections of skin, nails and mucous membranes caused mainly by Candida albicans $[1,2]$. The factors that predispose host to CMC infection could be autosomal or acquisitive. Increasing evidence indicates that some immunologic and hormonal abnormalities are associated with CMC due to changes of cellular immunity, which then lead to subsequent autoimmune endocrine disorders [3, 4]. To date, heterozygous gain-offunction (GOF) mutations of signal transducer and activator of transcription 1 (STAT1) have been identified as a cause of CMC [5-7]. Afterwards, many studies have proved that mutations at different sites of STAT1 are associated with the pathogenesis of CMC [8-10].

\footnotetext{
* Correspondence: lifuqiu1234@126.com

${ }^{1}$ Department of Dermatology, the Second Hospital of Jilin University, No.

218, Ziqiang street, Nanguan district, Changchun 130000, China

Full list of author information is available at the end of the article
}

Currently, azole anti-fungal drugs have been widely used for treating $\mathrm{CMC}$ as they show satisfactory bioavailability and safety. Unfortunately, there are an increasing number of resistant strains of Candida spp. in the presence of long-term azoles exposure. The potential mechanisms are associated with up-regulation of pharmaceutical transporters, over-expression or alteration of the drug target, as well as cellular changes caused, in some cases, by non-target effects induced by stress response [11].

In this study, we investigated the mechanism of azoleresistent $C$. albicans isolated from oral cavity in a CMC patient. We aim to remind the physicians that patients with congenital immunodeficiency should be monitored for the emergence of yeasts resistant to antifungals when they are on long-term medication. Also, it is necessary to pay attention to whether new drug resistance would be generated in immunodeficiency hosts.

(c) The Author(s). 2020 Open Access This article is distributed under the terms of the Creative Commons Attribution 4.0 International License (http://creativecommons.org/licenses/by/4.0/), which permits unrestricted use, distribution, and reproduction in any medium, provided you give appropriate credit to the original author(s) and the source, provide a link to the Creative Commons license, and indicate if changes were made. The Creative Commons Public Domain Dedication waiver (http://creativecommons.org/publicdomain/zero/1.0/) applies to the data made available in this article, unless otherwise stated. 


\section{Case presentation}

\section{Clinical information}

A 15-year-old boy was admitted to the Dermatology Department of the Second Hospital of Jilin University due to recurrent thrush for more than 10 years. The patient was of full-term normal delivery, with non-consanguineous marriage of his parents. Family history revealed no members with relevant infectious diseases, genetic abnormalities or immunodeficiencies. During the long course, the patient had been taking oral azole antifungal drugs intermittently for many years and the specific dose was unknown.

\section{Clinical examination findings}

There was obvious white membrane on his oral mucous membranes and tongue, which was cracked with pain. There were erythema and papules on his face (Fig. 1a). The right sided toenails were hyperkeratotic with brown discoloration for many years (Fig. 1b).

\section{Laboratory findings}

Direct microscopic examination of mucous samples, which were obtained from patient's oral cavity by sterile swabs, revealed the presence of yeast cells along with pseudohyphae, resembling Candida spp. infection (Fig. 1c). Typical white creamy yeast colonies were grown on Sabouraud Dextrose Agar (SDA, Fig. 1d). C. albicans was identified as the causative agent by sequencing of internal transcribed spacer region (ITS). Anti-fungal drugs susceptibility test showed that the minimun inhibitory concentration (MIC) of anidulafungin, micafungin, caspofungin, 5-flucytosine, posaconazole, voriconazole, itraconazole, fluconazole, and amphotericin B were $0.125 \mu \mathrm{g} / \mathrm{m} \mathrm{L}$, $0.06 \mu \mathrm{g} / \mathrm{m} \mathrm{L}, 0.25 \mu \mathrm{g} / \mathrm{m} \mathrm{L}, 0.125 \mu \mathrm{g} / \mathrm{m} \mathrm{L},>8 \mu \mathrm{g} / \mathrm{m} \mathrm{L},>8 \mu \mathrm{g} /$ $\mathrm{m} \mathrm{L},>16 \mu \mathrm{g} / \mathrm{m} \mathrm{L},>256 \mu \mathrm{g} / \mathrm{m}$, and $1 \mu \mathrm{g} / \mathrm{m} \mathrm{L}$. respectively. Lymphocytes analysis showed CD4+/CD8+ 1.02 (normal range 1.06-2.66), CD3-CD19+22.0\% (normal range 5.018.0), $\mathrm{CD} 3-\mathrm{CD}(16+56)+4.7 \%$ (normal range $7.0-26.0$ ), other laboratory examinations, including complete blood count, serum immunoglobulin levels, and serum complement levels were normal. Glycemia, thyroid, parathyroid and adrenal hormones were within physiological limits.

\section{Diagnosis and treatment}

On the basis of all the above findings, we made a diagnosis of CMC with resistant to azoles. However, after informing the patient and his family of the currently feasible treatments and considering the economic status of the patient's family, the patient was still treated with itraconazole $200 \mathrm{mg}$ (bid, PO). Fortunately, partial improvement was observed after 1 week. The patient is still under treatment now.
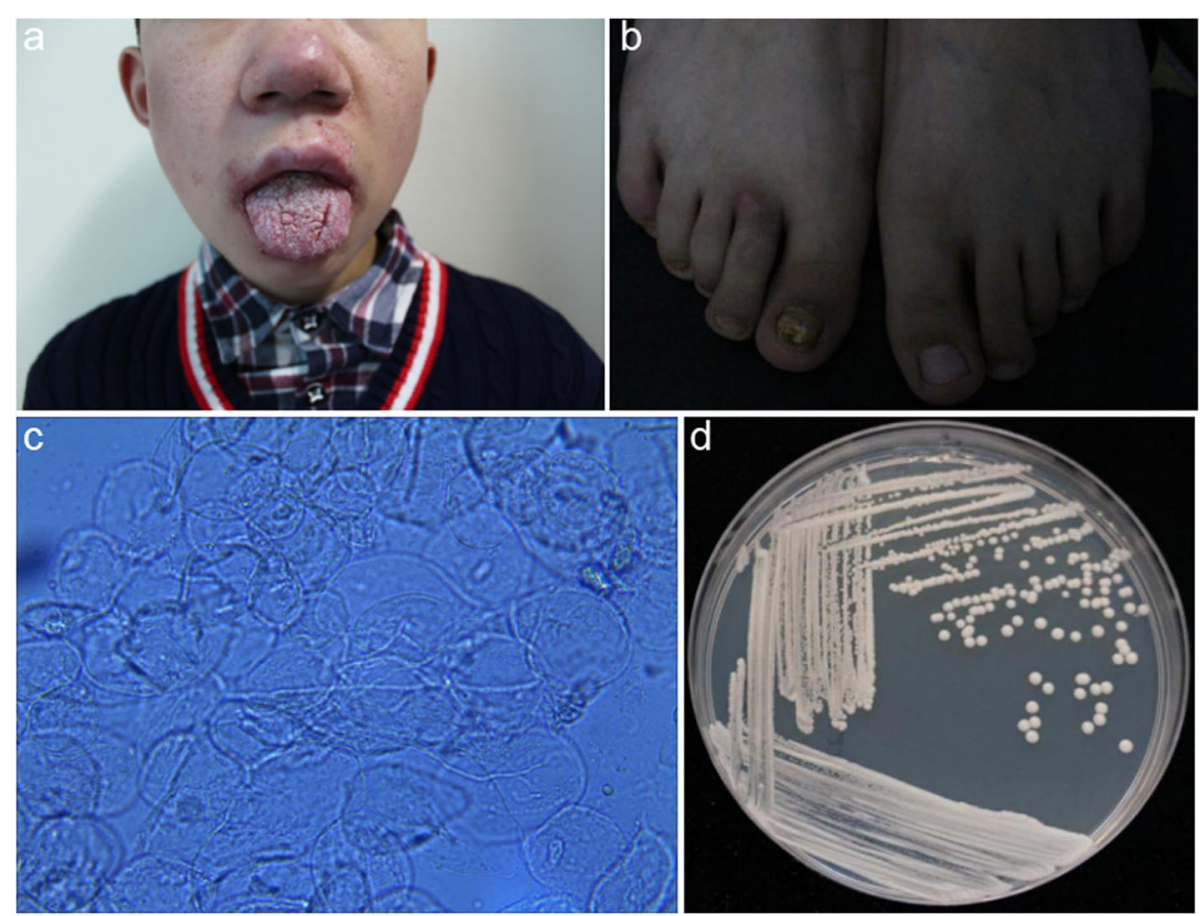

Fig 1 Clinical manifestations and mycological examinations of the patient. a Obvious white membrane was observed on the oral mucous membranes and tongue, which was cracked with pain. Erythema and papules were scattered on his face; $\mathbf{b}$ his right toenails was hyperkeratotic with brown discoloration; c, Direct microscopic examination of mucous samples revealed the presence of yeast cells along with pseudohyphae. d, Fungal culture reveals white creamy yeast colonies (SDA, 2 days at $28^{\circ} \mathrm{C}$ ) 


\section{Mutation in STAT1}

After signing the informed consent, peripheral blood was extracted by QIAamp DNA Blood Mini Kit (QIAGEN, Hilden, Germany). All exons of STAT1 were amplified by PCR. Sequencing was performed by Sangon Biotech (Shanghai, China). A heterozygous mutation (c.1162A > G, p.K388E) was identified in exon 14 of the patient (Fig. 2a and b). Such mutation was not identified in the samples from his parents (Fig. 2c and d).

\section{ERG3 and ERG11 sequencing}

C. albicans strain, termed as CA-R, was isolated from the oral cavity of the patient. The type strain SC5314 served as control. All strains were routinely cultured on yeast extract peptone dextrose medium (YPD) at $37^{\circ} \mathrm{C}$ under constant stirring of $220 \mathrm{rpm} / \mathrm{min}$ for $12-24 \mathrm{~h}$. C. albicans genomic DNA was extracted as described previously [12]. The extracted DNA was used as template for amplification of the full-length ERG3 and ERG11 genes, using the specific primers listed in Table 1. Compared with SC5314 strain, 8 nucleotide substitutions were identified in ERG11 gene of CA-R and 6 nucleotide substitutions were identified in ERG3, respectively. Among these substitutions, 13 were synonymous mutations and 1 was missense mutations of ERG11 resulting in amino acid changes (p.E266D, Table 2). Amino acid exchange (E266D) was identified in fluconazole resistant isolates, however, such sequence differences may simply reflect the allelic variation.

\section{Over-expression of drug efflux pump genes}

RNA was isolated using RNeasy Mini Kit (QIAGEN, Hilden, Germany) according to the manufacturer's instructions. The cDNA was synthesized with $1 \mu \mathrm{g}$ RNA using the PrimeScriptTM RT Reagent Kit with gDNA Eraser (TaKaRa). RT-PCR was performed for independent amplification of internal reference gene (18S rRNA) and ERG11, CDR1, CDR2 genes to be quantified from the same cDNA template using a 7300 Real-Time PCR System (Applied Biosystems, Shanghai, China), with SYBR Premix Ex Taq (Tli RNaseH Plus. TaKaRa) using the primers listed in Table 1. PCR cycling conditions were $95{ }^{\circ} \mathrm{C}$ for $5 \mathrm{~min}$, followed by 40 cycles of $95^{\circ} \mathrm{C}$ for $5 \mathrm{~s}$ and appropriate annealing temperature for $30 \mathrm{~s}$. SPSS 19.0 software was used for the analysis. The data were expressed as mean \pm standard deviation (SD). The CT

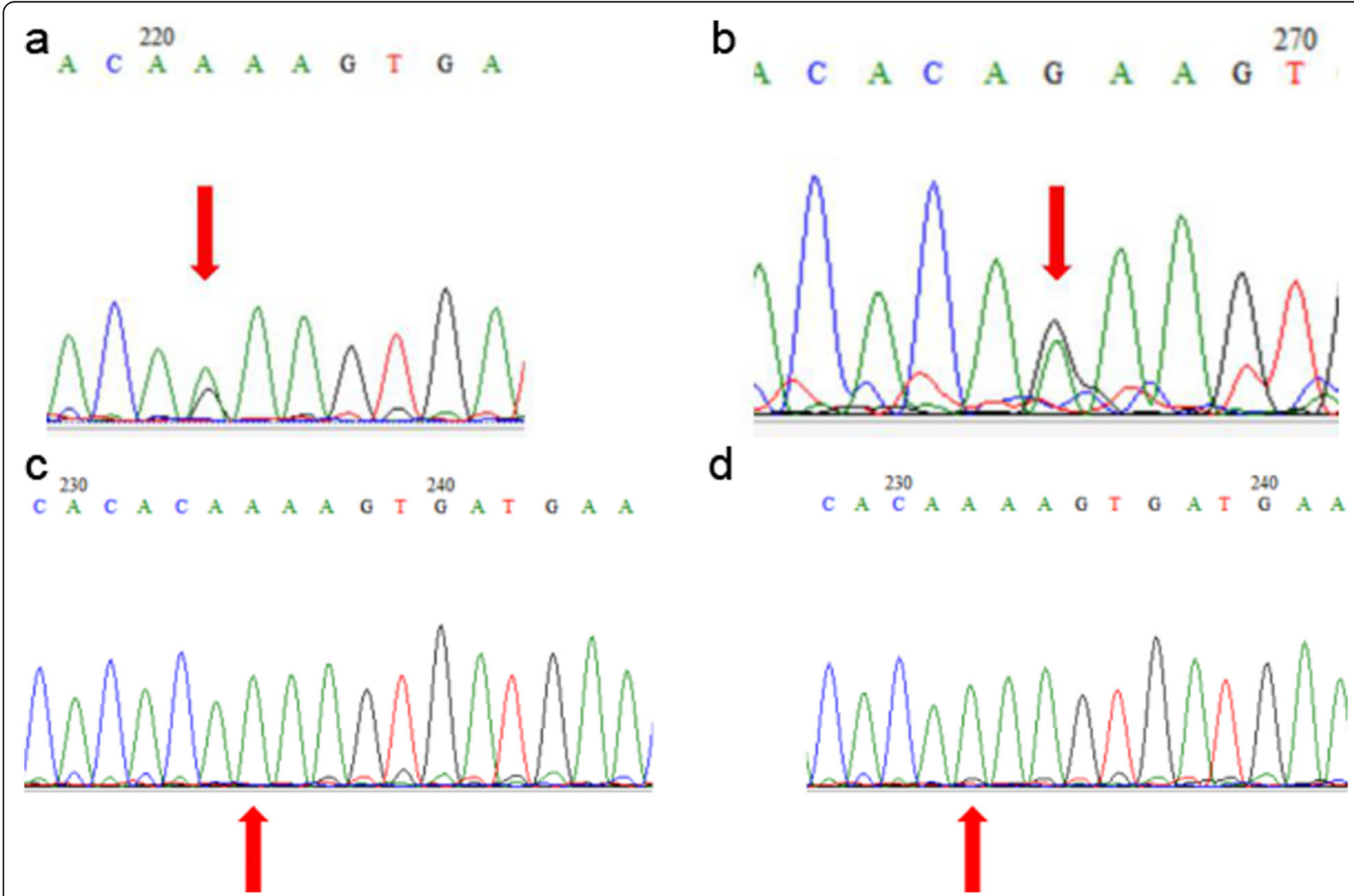

Fig 2 Direct sequencing analysis of STAT1 exon 14 in patient and his parents. Forward (a) and reverse (b) sequence of the patient, forward sequence of the father $(\mathbf{c})$ and mother $(\mathbf{d})$ were shown. Patient had the heterozygous base change of c.1162A > G resulting in p.K388E in STAT1. The sequences of parents were normal 
Table 1 Primer sequences and annealing temperatures

\begin{tabular}{llc}
\hline Name & Sequences $\left(5^{\prime}-3^{\prime}\right)$ & Annealing temperature $\left({ }^{\circ} \mathrm{C}\right)$ \\
\hline ERG3-F & GATCATAACTCAATATGG & 60 \\
ERG3-R & CTGAACACTGAATCG & 60 \\
ERG11-F & ATGGATATCGTACTAGAA & \\
ERG11-R & TCATTGTTCAACATATTC & 58 \\
18S-F & TCTTCTTGATTTGTGGGTGG & \\
18S-R & TCGATAGTCCCTCTAAGAAGTG & 60 \\
CDR1-F & GCTGGTGAAGGTTGAATGT & \\
CDR1-R & CGCTGATGGTTATGGATAG & 54 \\
CDR2-F & ATCTGGTGCTGGTAAGAC & \\
CDR2-R & GCTGATGGTTGATGGATAG & \\
\hline
\end{tabular}

value of $18 \mathrm{~S}$ rRNA was subtracted from the detected genes to obtain a ${ }^{\Delta} \mathrm{CT}$ value. The ${ }^{{ } \mathrm{CT}}$ value of type material was subtracted from the ${ }^{\Delta} \mathrm{CT}$ value of CA-R to obtain ${ }^{{ }^{\Delta}} \mathrm{CT}$. The relative quantification was performed using the $2^{-\triangle \Delta C T}$ method [13]. Expression of ERG11, CDR1 and CDR2 mRNA was detected in SC5314 and CA-R. The expression of CDR1 mRNA in CA-R was about 4.28-fold than that of the SC5314, while the expression of CDR2 mRNA in CA-R was about 5.25-fold than that of SC5314. The expression of ERG11 mRNA in CA-R was about 0.79 -fold than that of the SC5314 (Table 3).

\section{Discussion and conclusions}

Candida are normally non-pathogenic microorganisms in human beings. However, they are the major opportunistic fungal pathogens causing surface and invasive infections in individuals, which is associated with significant morbidity

Table 2 Amino acid changes in ERG11 and ERG3 protein

\begin{tabular}{lll}
\hline Location & & AA changes \\
\hline ERG11 & 798 & p.L220L \\
& 996 & p.E266D \\
& 1026 & p.V332V \\
& 1110 & p.K342K \\
& 1203 & p.L370L \\
& 1296 & p.Y401Y \\
& 1302 & p.A432A \\
& 51 & p.A434A \\
ERG3 & 306 & p.Y27Y \\
& 381 & p.T102T \\
& 402 & p.T127T \\
& 432 & p.Y134Y \\
438 & p.F144F \\
\end{tabular}

${ }^{a}$ reported to be unrelated to azole resistance of $C$. albicans
Table 3 Drug efflux pump gene mRNA relative expression levels of CDR1, CDR2 and ERG11

\begin{tabular}{llll}
\hline & $C D R 1$ & $C D R 2$ & ERG11 \\
\hline${ }^{-x \pm S D(\Delta \Delta C T)}$ & $-2.099 \pm 0.189$ & $-2.392 \pm 0.478$ & $0.348 \pm 0.218$ \\
$2^{-\Delta \Delta C T}$ & 4.28 & 5.25 & 0.79 \\
\hline
\end{tabular}

and mortality [9]. Immunosuppressive therapy, mucous damage, indwelling catheters, and prolonged hospital stay are the risk factors for Candida infection [14]. Besides, genetic factors must play a role in the pathogenesis of Candida infections, especially invasive candidiasis and CMC.

Several genes affecting the anti-fungal immunity have been reported to be associated with the pathogenesis of CMC, including AIRE, CLEC7A, CARD9, IL17RA, IL17F, IL2R $\alpha$, Dectin-1, STAT1 and STAT3 [5-7, 15-20]. STAT1, one of the seven transcription factors of the STAT family, is the major signaling components of interferon responses. In the presence of interferon binding to its receptor, STAT1 is activated by tyrosine phosphorylation [21]. Upon forming a dimer, STAT1 enters the nucleus and triggers the transcription of its targets. Such process plays a pivotal role in the defense against pathogens. The mutations of STAT1 were considered as a GOF type because of a gain of phosphorylation and a loss of nuclear dephosphorylation. In a previous study, Van de Veerdonk et al. [6] demonstrated that patients with heterozygous missense mutations in the coiled-coil domain of STAT1 had deficiencies in mounting TH1 and TH17 responses due to defective IL-12 receptor and IL-23 receptor signaling pathways [7]. S. Takezaki et al. [8] firstly reported that the GOF mutations of DNA-binding domain were also the genetic cause of $C M C$, which involved a gain of STAT1 function due to impaired dephosphorylation in the coiled-coil domain mutations.

In this case, direct sequence analysis of STAT1 exons indicated presence of c.1162A > G, which then resulted in p.K388E in exon 14. As previously described [10, 22], K388E was a GOF mutation in the DNA-binding domain. The patients showed an early onset and received different systemic or topical anti-fungal treatments for more than 10 years, especially azoles. Long-term azoles exposure may lead to generation of $C$. albicans resistant strains. Therefore, we speculated that the azolesresistant $C$. albicans isolated from this case was induced by long-term exposure of anti-fungal drugs.

Azole drugs can target the ergosterol bio-synthetic pathway. Ergosterol is a crucial component of membrane of the fungal cell. Interruption of its synthesis allows accumulation of $14 \alpha$-methyl sterols, which is encoded by ERG11 in Candida spp. The function of $14 \alpha$-methyl sterols is to alter the membrane stability, permeability, and the action of membrane-bound enzymes [23, 24]. Additionally, inhibition of ERG3, a $\Delta^{5,6}$-desaturase could lead 
to a depletion of ergosterol and accumulation of 14amethylfecosterol, which allowed continuous growth in the presence of azole despite altered membrane composition [25]. Also, ERG11 over-expression confers azole resistance, which is more common among azole resistant isolates of C. albicans [26]. Over-expression of efflux pumps, encoded by genes of the ATP-binding cassette (ABC) super-family or the major facilitator super-family (MFS), is the most common cause for drug resistance. Such process could decrease the intracellular drug concentration by increasing target abundance. Hence, more drugs are required to inhibit the activity of pathogens, which then results in reduction of drug susceptibility [27].

To further investigate the resistance mechanism of $C$. albicans in this case, we sequenced ERG11 and ERG3. In total, 14 nucleotide substitutions were detected in ERG11 and ERG3, among which 13 nucleotide substitutions were synonymous mutations and 1 was missense mutations of ERG11 resulted in amino acid changes (p.E266D). In the previous study, such mutation was not reported to be related to azole resistance in C. albicans [28]. Additionally, RT-PCR was performed to detect the expression of CDR1, CDR2 and ERG11 mRNA between CA-R and the type strain SC5314. The relative expression of CDR1 and CDR2 rather than ERG11 in multiple azole resistant strains was obviously higher than that of SC5314 strain. These suggested that the main cause for azoles-resistant CA- $\mathrm{R}$ may be related to the overexpression of CDR1 and CDR2.

Several aspects have been reported to affect the expression of the azole target and/or drug pumps, including mutations in the drug target enzyme and efflux pumps over-expression, loss of heterozygosity, increased chromosomal copy number, aneuploidy, as well as the isochromosome [29]. These constituted the main reasons of azole resistance of $C$. albicans together with the biofilm formation [30]. They can occur in a single set or concurrently, which can produce additive effects or lead to cross-resistance among azoles. In this study, we only focused on the determination of drug efflux pump genes and target enzyme sequence. In future, additional studies are required to investigate whether there are other causes of drug resistance.

With the increasing understanding on CMC mutation mechanism, strategies based on the defects in STAT1 GOF mutations may serve as a candidate for treating CMC, such as decreasing hyperphosphorylation of STAT1 and restoring Th17 function by blocking inhibitory mechanisms [31]. However, the efficacy of these treatment options has not been well confirmed. Therefore, long-term systemic application of anti-fungal drugs is often preferred in clinical settings. Clinically, within a safe range, these patients were usually given a higher therapeutic dose of the drugs. After the symptoms were controlled, it was gradually reduced and finally the maintenance treatment was performed at the smallest controllable dose. Drug exposure in the form of prophylaxis, repeated, or long-term therapy is associated with the emergence of resistance [30]. At present, there are no system reports about anti-fungal drugs susceptibility of pathogen in CMC patients, who were receiving longterm oral anti-fungal treatment. Therefore, further investigations are still needed. Over-expression of the efflux pump was mainly responsible for the drug resistance. Efflux pump over-expression will reduces the entry of the drug into the pathogens, thereby reducing the effect of the drug. However, in presence of increased extracellular drug concentration, it may still be effective [30]. Although the pathogen in this case is resistant to the multiple azoles, the anti-fungal drug is still selected after informing the patient and his family of the currently feasible treatment options. Fortunately, the symptoms showed remission after administration of itraconazole in this case.

There are some limitations in this study. Firstly, there was only one case. Although the number of studies on gene mutation induced CMC showed increase, there are still rare cases in clinical settings. Secondly, we only investigated the over-expression of target genes encoding the enzyme and the mutation of target genes. We did not investigate the roles of other drug-resistant mechanisms.

In conclusion, we reported a case of CMC with multiple azole-resistant $C$. albicans, and investigated the possible mechanism of the drug resistance. The expression of $C D R 1$ and $C D R 2$ gene was up-regulated. For special patients, such as CMC or other immunodeficiency patients, drug resistance monitoring is very necessary.

\section{Abbreviations \\ ABC: ATP-binding cassette superfamily; CMC: Chronic mucocutaneous candidiasis; CT: Cycle threshold; GOF: Gain-of-function; ITS: Internal transcribed spacer region; MFS: Major facilitator superfamily; MIC: Minimun inhibitory concentration; PCR: Polymerase chain reaction; qRT- PCR: Quantitative real-time reverse transcription PCR; SDA: Sabouraud Dextrose Agar; STAT1: Signal transducer and activator of transcription 1}

\section{Acknowledgements}

We thank the patient and his parent for participation in this study. We also thank Xiaowen Wang (Department of Dermatology, Peking University First Hospital; Beijing Key Laboratory of Molecular Diagnosis on Dermatoses, Beijing, China) for the primers and the identification of the mutation of STAT1, Zhe Wan and Yabin Zhou (Department of Dermatology, Peking University First Hospital; Beijing Key Laboratory of Molecular Diagnosis on Dermatoses, Beijing, China) for identification of the pathogen and in vitro anti-fungal drugs susceptibility test.

\section{Authors' contributions}

ZY, LS, WS: clinical data analysis, diagnosis, treatment, follow-up; MY, ZF, YCL: did the experiments, and analyzed data; ZMR: writing the manuscript; LFQ: revised the manuscript; All authors read and approved the final manuscript. 


\section{Availability of data and materials}

The datasets used and/or analyzed during the current study are available from the corresponding author on reasonable request.

\section{Ethics approval and consent to participate}

This study was approved by the Clinical Research Ethics Committee of the Second Hospital of Jilin University, protocol number 2018-018.

\section{Consent for publication}

Written informed consent was obtained from the patient's parent for publication of this Case report and any accompanying images. A copy of the written consent is available for review by the Editor of this journal. The study protocols were approved by the Ethical Committee of the Second Hospital of Jilin University.

\section{Competing interests}

The authors declare that they have no competing interests.

\section{Author details}

'Department of Dermatology, the Second Hospital of Jilin University, No. 218, Ziqiang street, Nanguan district, Changchun 130000, China. ${ }^{2}$ National Institute for Communicable Disease Control and Prevention, Chinese Center for Disease Control and Prevention, State Key Laboratory of Infectious Disease Prevention and Control, Beijing, China.

\section{Received: 11 November 2019 Accepted: 6 February 2020}

Published online: 11 February 2020

\section{References}

1. Lilic D. New perspectives on the immunology of chronic mucocutaneous candidiasis. Curr Opin Infect Dis. 2002;15(2):143-7.

2. Kirkpatrick CH. Chronic mucocutaneous candidiasis. J Am Acad Dermatol. 1994;31(3 Pt 2):S14-7.

3. Mathis D, Benoist C. Aire. Annu Rev Immunol. 2009:27:287-312.

4. Coleman R, Hay RJ. Chronic mucocutaneous candidosis associated with hypothyroidism: a distinct syndrome? Br J Dermatol. 1997;136(1):24-9.

5. Liu L, Okada S, Kong XF, Kreins AY, Cypowyj S, Abhyankar A, Toubiana J, Itan Y, Audry M, Nitschke P, et al. Gain-of-function human STAT1 mutations impair IL-17 immunity and underlie chronic mucocutaneous candidiasis. J Exp Med. 2011;208(8):1635-48.

6. van de Veerdonk FL, Plantinga TS, Hoischen A, Smeekens SP, Joosten LA, Gilissen C, Arts P, Rosentul DC, Carmichael AJ. Smits-van der Graaf CA et al: STAT1 mutations in autosomal dominant chronic mucocutaneous candidiasis. N Engl J Med. 2011;365(1):54-61.

7. Smeekens SP, Plantinga TS, van de Veerdonk FL, Heinhuis B, Hoischen A Joosten LA, Arkwright PD, Gennery A, Kullberg BJ, Veltman JA, et al. STAT1 hyperphosphorylation and defective IL12R/L23R signaling underlie defective immunity in autosomal dominant chronic mucocutaneous candidiasis. PLoS One. 2011;6(12):e29248.

8. Takezaki S, Yamada M, Kato M, Park MJ, Maruyama K, Yamazaki Y, Chida N, Ohara O, Kobayashi I, Ariga T. Chronic mucocutaneous candidiasis caused by a gain-of-function mutation in the STAT1 DNA-binding domain. J Immunol. 2012;189(3):1521-6.

9. Wang X, van de Veerdonk FL, Netea MG. Basic genetics and immunology of Candida infections. Infect Dis Clin N Am. 2016;30(1):85-102.

10. Wang X, Zhang R, Wu W, Wang A, Wan Z, van de Veerdonk FL, Li R. New and recurrent STAT1 mutations in seven Chinese patients with chronic mucocutaneous candidiasis. Int J Dermatol. 2017;56(2):e30-3.

11. Cowen LE, Sanglard D, Howard SJ, Rogers PD, Perlin DS. Mechanisms of antifungal drug resistance. Cold Spring Harb Perspect Med. 2014;5(7): a019752.

12. Versalovic J, Koeuth T, Lupski JR. Distribution of repetitive DNA sequences in eubacteria and application to fingerprinting of bacterial genomes. Nucleic Acids Res. 1991;19(24):6823-31.

13. Livak KJ, Schmittgen TD. Analysis of relative gene expression data using real-time quantitative PCR and the 2(-Delta Delta C(T)) Method. Methods (San Diego, Calif). 2001;25(4):402-8.

14. Das I, Nightingale P, Patel M, Jumaa P. Epidemiology, clinical characteristics, and outcome of candidemia: experience in a tertiary referral center in the UK. Int J Infect Dis. 2011;15(11):e759-63.
15. Nagamine K, Peterson P, Scott HS, Kudoh J, Minoshima S, Heino M, Krohn $\mathrm{K}$, Lalioti MD, Mullis PE, Antonarakis SE, et al. Positional cloning of the APECED gene. Nat Genet. 1997;17(4):393-8.

16. Finnish-German APECED Consortium. An autoimmune disease, APECED, caused by mutations in a novel gene featuring two PHD-type zinc-finger domains. Nat Genet. 1997;17(4):399-403.

17. Ferwerda B, Ferwerda G, Plantinga TS, Willment JA, van Spriel AB, Venselaar H, Elbers CC, Johnson MD, Cambi A, Huysamen C, et al. Human dectin-1 deficiency and mucocutaneous fungal infections. N Engl J Med. 2009; 361(18):1760-7.

18. Glocker EO, Hennigs A, Nabavi M, Schaffer AA, Woellner C, Salzer U, Pfeifer D, Veelken $\mathrm{H}$, Warnatz $\mathrm{K}$, Tahami F, et al. A homozygous CARD9 mutation in a family with susceptibility to fungal infections. N Engl J Med. 2009;361(18):1727-35.

19. Puel A, Cypowyj S, Bustamante J, Wright JF, Liu L, Lim HK, Migaud M, Israel L, Chrabieh M, Audry M, et al. Chronic mucocutaneous candidiasis in humans with inborn errors of interleukin-17 immunity. Science (New York, NY). 2011:332(6025):65-8.

20. Sharfe N, Dadi HK, Shahar M, Roifman CM. Human immune disorder arising from mutation of the alpha chain of the interleukin-2 receptor. Proc Natl Acad Sci U S A. 1997;94(7):3168-71.

21. Najjar I, Fagard R. STAT1 and pathogens, not a friendly relationship. Biochimie. 2010:92(5):425-44.

22. Frans $G$, Moens $L$, Schaballie $H$, Van Eyck L, Borgers H, Wuyts M, Dillaerts D, Vermeulen E, Dooley J, Grimbacher B, et al. Gain-of-function mutations in signal transducer and activator of transcription 1 (STAT1): chronic mucocutaneous candidiasis accompanied by enamel defects and delayed dental shedding. J Allergy Clin immunol. 2014;134(5):1209-0 e1206.

23. White TCHS, Dy F, et al. Resistance mechanisms in clinical isolates of Candida albicans. Antimicrob Agents Chemother. 2002;46:1704-13.

24. Odds FC, Brown AJ, Gow NA. Antifungal agents: mechanisms of action. Trends Microbiol. 2003;11(6):272-9.

25. Lupetti A, Danesi R, Campa M, Del Tacca M, Kelly S. Molecular basis of resistance to azole antifungals. Trends Mol Med. 2002;8(2):76-81.

26. Flowers SA, Barker KS, Berkow EL, Toner G, Chadwick SG, Gygax SE, Morschhauser J, Rogers PD. Gain-of-function mutations in UPC2 are a frequent cause of ERG11 upregulation in azole-resistant clinical isolates of Candida albicans. Eukaryot Cell. 2012;11(10):1289-99.

27. Akins RA. An update on antifungal targets and mechanisms of resistance in Candida albicans. Med Mycol. 2005;43(4):285-318.

28. Morschhauser J. The genetic basis of fluconazole resistance development in Candida albicans. Biochim Biophys Acta. 2002;1587(2-3):240-8.

29. Selmecki A, Forche A, Berman J. Aneuploidy and isochromosome formation in drug-resistant Candida albicans. Science (New York, NY). 2006;313(5785):367-70.

30. Perlin DS, Rautemaa-Richardson R, Alastruey-Izquierdo A. The global problem of antifungal resistance: prevalence, mechanisms, and management. Lancet Infect Dis. 2017:17(12):e383-92.

31. van de Veerdonk FL, Netea MG. Treatment options for chronic mucocutaneous candidiasis. The Journal of infection. 2016;72(Suppl):S56-60.

\section{Publisher's Note}

Springer Nature remains neutral with regard to jurisdictional claims in published maps and institutional affiliations.

\section{Ready to submit your research? Choose BMC and benefit from:}

- fast, convenient online submission

- thorough peer review by experienced researchers in your field

- rapid publication on acceptance

- support for research data, including large and complex data types

- gold Open Access which fosters wider collaboration and increased citations

- maximum visibility for your research: over $100 \mathrm{M}$ website views per year

At BMC, research is always in progress.

Learn more biomedcentral.com/submissions 